JEAN-FrANÇOIS CHÉNIER, Communiquer

l'incommunicable. Une lecture des cuvres de Georges Bataille et de Pierre Klossowski

\title{
Luigi Magno
}

\section{(2) OpenEdition}

\section{Edizione digitale}

URL: https://journals.openedition.org/studifrancesi/12155

DOI: $10.4000 /$ studifrancesi. 12155

ISSN: 2421-5856

\section{Editore}

Rosenberg \& Sellier

\section{Edizione cartacea}

Data di pubblicazione: 1 avril 2018

Paginazione: 170

ISSN: 0039-2944

\section{Notizia bibliografica digitale}

Luigi Magno, "Jean-François Chénier, Communiquer l'incommunicable. Une lecture des œuvres de Georges Bataille et de Pierre Klossowski», Studi Francesi [Online], 184 (LXII | I) | 2018, online dal 03 juillet 2018, consultato il 18 novembre 2021. URL: http://journals.openedition.org/studifrancesi/12155 ; DOI: https://doi.org/10.4000/studifrancesi. 12155

Questo documento è stato generato automaticamente il 18 novembre 2021.

\section{(c) $(1) \odot$}

Studi Francesi è distribuita con Licenza Creative Commons Attribuzione - Non commerciale - Non opere derivate 4.0 Internazionale. 


\title{
JeAn-FrançoIs ChÉNIER, Communiquer l'incommunicable. Une lecture des œuvres de Georges Bataille et de Pierre Klossowski
}

\author{
Luigi Magno
}

\section{NOTIZIA}

JEAN-FrançOIS CHÉNIER, Communiquer l'incommunicable. Une lecture des œuvres de Georges Bataille et de Pierre Klossowski, Paris, L'Harmattan, 2017, «Espaces Littéraires», 304 pp.

1 La lettura di alcuni testi di Georges Bataille nel primo capitolo del saggio («Bataille et le “système” du bouleversement analogue») - Histoire d'œil, la trilogia Divinus Deus e L'abbé C. - e di Pierre Klossowski nel secondo («Pierre Klossowski: du simulacre à la révélation du signe unique») - La vocation suspendue, Le bain de Diane, la trilogia Les lois de l'hospitalité e Le Baphomet - prende essenzialmente le mosse da due evidenze che sono altrettante comunanze. Da un lato l'ibridazione formale e generica dei testi, che trova il suo fulcro nell'inscindibile fusione tra una dimensione teorico-riflessiva e una linea mitico-diegetica, dall'altro uno stesso fine che, in apparenza aporetico, risiede nel tentativo di trasmettere (e suscitare) un residuo intransitivo, pulsionale e affettivo, dunque per sua natura incomunicabile.

Il saggio solleva dapprima il problema di un'epistemologia letteraria (o dell'esistenza di una parte epistemica della letteratura), riconducendolo non solo alla sua fase liminale, dunque al dibattito suscitato dalla Poetica di Aristotele e dal terzo libro della Repubblica di Platone, ma anche a un suo momento di svolta, che per Bataille e Klossowski si colloca nella riflessione di Nietzsche. Il filosofo tedesco, infatti, dubita della verità come concetto razionale e frutto di un pensiero cosciente. Rivalutando l'individualità e l'istanza impulsiva, vedi inconscia e stocastica, Nietzsche associa l'interpretazione a un 
pathos singolare, specifico non solo a ogni individuo ma anche a ogni situazione di comunicazione, dunque irrazionale, irriducibile e non passibile di categorizzazione. Sulla scorta della lezione di Al di là del bene e del male o della Genealogia della morale, Bataille e Klossowski pensano il proprio lavoro letterario come "conoscenza patica". Entrambi rivalutano l'hybris come forma di una scienza del sensibile. Bataille, via Sade, lavora così su nuclei tematici legati al male, all'abiezione, all'eccesso, mentre Klossowski riabilita, in prospettiva anti-platonica, i simulacri, crea contesti dove tutto è simulacro (dunque frutto di interpretazione) e l'originale stesso è copia, utilizza un linguaggio sospeso tra l'immagine mentale e il tableau vivant. In questo modo il sensibile si trova, mutatis mutandis, proiettato a rango del vero (o della verità), dunque di conoscenza (patica o patetica).

Riaffermata la caducità di ogni separazione tra logos e mythos (difesa invece da Platone), per Klossowski e Bataille la letteratura è dunque il luogo di un'esperienza estetica che trasmette un sentire affettivo-pulsionale tanto inedito quanto indocile alla formulazione, senza senso, non conoscibile. La terza e ultima parte del volume («Communauté sensible, communauté secrète ou l'expérience sacrée») analizza proprio le finalità di una tale visione della narrativa, orientata principalmente alla creazione di una "comunità" - di volta in volta "sensibile", "sacra", "segreta" - (Bataille), o ancora di una "complicità" (Klossowski). Mettere al centro della narrazione un sapere o una conoscenza che sfuggono a ogni tentativo di definizione razionale mira a distogliere l'attenzione del lettore dalla linea diegetica per spostarla sul pathos, le emozioni, gli affetti e le pulsioni che circolano nei racconti. Detta di volta in volta «expérience intérieure», «non-savoir», «sacré», «extase» (Bataille) o, ancora, «connaissance pathétique» (Klossowski), l'emozione sensibile ha lo scopo di sollecitare la reazione affettiva del lettore. Facendo perno su un «bouleversement analogue» (Bataille), i testi di Bataille e di Klossowski sono dunque allo stesso tempo una messa in scena del pathos e un dispositivo che mira a suscitare il pathos. In questo senso la finzione del racconto può dirsi epistemica. Prendendo in contropiede la concezione sartriana (che mette il pensiero razionale all'origine del racconto), i testi rivelano infine una forma di «engagement inverse» (Denis Hollier) e si pongono al servizio, almeno nelle intenzioni teoriche dei loro autori, della creazione di comunità. Radunate attorno a un sensus communis, queste saranno il luogo in cui si attiveranno processi di ridiscussione dei valori comuni, luogo dunque di una rifondazione parimenti etica ed epistemica. 